\title{
Evaluation Index of Equipment Utilization Efficiency in Substation Considering Distributed Generation
}

\author{
Xiaojian Chen ${ }^{1}$, Xiang $\mathrm{Li}^{1}$, Fenglu $\mathrm{He}^{2}$ and Ziheng Zhang ${ }^{3}$ \\ ${ }^{1}$ China Southern Power Grid Co.Ltd, Shaoguan Power Supply Bureau, No. 66, Gongyexi Road, Shaoguan, China \\ ${ }^{2}$ Guangzhou Power Electrical Technology Co. Ltd, System Research Division, Room 440, Building C, Wushan Technology \\ Square, Wushan Road Tianhe, Guangzhou, China \\ ${ }^{3}$ South China University of Technology, School of Electric Power, No. 381, Wushan Road Tianhe, Guangzhou, China
}

\begin{abstract}
With the development of Distributed Generation (DG), traditional evaluation index of equipment utilization efficiency is not objective in some situations. To solve this problem, a comprehensive evaluation method of equipment utilization efficiency in substation is proposed in this paper. Based on the characteristics of distribution network including DG, two indexes, the burden rate and the load rate, are considered. Then, the indexes are further analyzed that they are specified into the injected indexes and the bidirectional indexes. From the operation data of transformers, the specified indexes are calculated representatively and it is indicated that bidirectional indexes could reflect the equipment utilization efficiency in substation more objectively. The presented method provides a new perspective of evaluating the equipment utilization efficiency in substation considering DG.
\end{abstract}

\section{Introduction}

In the rural areas with low load density, $35 \mathrm{kV}$ and $10 \mathrm{kV}$ distribution systems play an important role in power distribution, and they are significant connection between Distributed Generation (DG) and the power Grid in rural areas. Evaluating transformer equipment utilization in $35 \mathrm{kV}$ substation scientifically is the base of operation economy and power system planning for power supply enterprise.

At present, power supply reliability, voltage profile and line loss are the most concerning indexes in evaluation of distribution network for power supply enterprise. Most of the equipment utilization efficiency research is carried on by other industries [1]-[3], and research in power grid is still relatively fewer. Indexes like maximum and average burden rate of the main transformer are chosen to reflect the equipment utilization efficiency in some papers. Reference [4] studies on how to improve the equipment utilization efficiency in mediumvoltage distribution network from the perspective of optimal burden rate of equipment. Based on the burden rate, the evaluation index system of equipment utilization efficiency in distribution network is established in [5]. Reference [6] proposes that the burden rate and the load rate should be considered simultaneously in evaluation of equipment utilization efficiency in distribution network. So the burden rate and the load rate could be used to analyze the transformer utilization efficiency in substation, but in distribution network including DG, like small hydropower, the traditional evaluation index is controversial. As electricity seller, the power supply enterprises generally focus on the injected load. But in rural distributed power grid, if only evaluate the transformer equipment utilization efficiency by injected burden rate and load rate, the index can't reflect the real contribution of the transformers when DG in operation.

Therefore, it is necessary to specify the indexes of burden rate and load rate to reflect the transformer utilization situation objectively when DG transmits power reversely.

\section{Definition of burden rate and load rate}

Burden rate is defined as the ratio of practical load to transformer capacity. Since there is evaluation period of equipment utilization efficiency in substation, the index of burden rate is specifically defined as the ratio of maximum active load to transformer capacity. The transformer loading capability is represented by burden rate, which shows the utilization level of equipment. However, burden rate only reflects the best utilized situation at a certain time point, and the utilized situation in a long period is unknown. Therefore, using the burn rate as the sole evaluation index would lead to imperfect and unilateral problem. So the evaluation indexes including load rate are needed.

Load rate is defined as the ratio of average load in a regulation period divided by maximum load, which reflects load variation in the regulation period and transformer utilization level. Under the consideration of economic operation, the transformer utilized situation 
would be better when load rate is closer to 1 , which means the load is smoother.

Therefore, burden rate and load rate are complementary indexes in the evaluation of transformer utilization efficiency, in which burden rate represents the ultimate transformer utilized situation at a time point, and load rate represents the transformer utilized situation in a long period.

\section{Analysis of equipment utilization efficiency in substation including DG}

Traditionally, it is net load that power supply enterprises focus on. In substation, net load is given by subtracting DG output from overall load, which is injected load from substation and the equation is shown in (1).

$$
P_{e q}=\sum_{i \in S_{L}} P_{L i}-\sum_{i \in S_{D G}} P_{D G i}
$$

where $P_{\text {eq }}$ is net load in substation, $P_{\mathrm{Li}}$ is load in power grid, $P_{\mathrm{DG}}$ is the output of DG, $S_{\mathrm{L}}$ is sets of loads in power grid and $S_{\mathrm{DG}}$ is sets of DGs.

When DG inversely transmitting power to main network, the uncertainty of net load is increase because of the DG fluctuation, which requires more reserve capacity of transformer and reduces the utilization efficiency.

\subsection{Specify the burden rate}

With DG in operation, it may result in inverted power transmission and the effect on burden rate is analyzed in Figure 1.

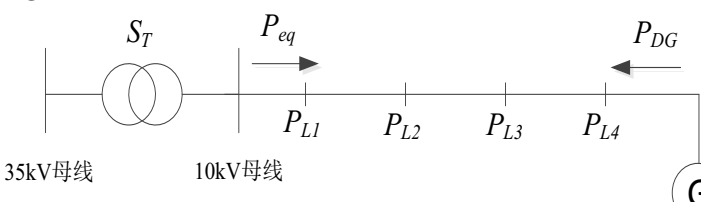

Figure 1. The inverse power flow with DG in operation.

Neglecting the line loss, it is obtained that $P_{e q}=\sum_{i=1}^{4} P_{L i}-P_{D G}$.

Assuming in evaluation period, the burden rate of transformer is referred to the ratio of maximum $\left|P_{\text {eq }}\right|$ to transformer capacity $\mathrm{S}_{\mathrm{T}}$ in traditional way. But when the DG output reaches a relatively large value like small hydropower in wet season, it may occur in $\max \left(\left|P_{\text {eq }}\right|\right)>$ $\max \left(P_{\text {eq }}\right)$. So it is not objective to evaluate the equipment utilization efficiency in substation by traditional burden rate.

However, from the perspective of power supply enterprises, considering the burden rate of transmission power in forward direction is reasonable in some way because only injected power could bring economic profit. So the burden rate is specified into the injected burden rate $\alpha_{1}$ representing the economic profit and the bidirectional burden rate $\alpha_{2}$ representing the equipment utilization efficiency in substation.
The formula of the injected burden rate is shown in (2).

$$
\alpha_{1}=\frac{P_{u d-\max }}{S_{T}}
$$

where $P_{\text {ud-max }}$ is the maximum value of injected load and $S_{\mathrm{T}}$ is transformer capacity.

The formula of the bidirectional burden rate is shown in (3).

$$
\alpha_{2}=\frac{P_{b d-\max }}{S_{T}}
$$

where $P_{\mathrm{bd}-\max }$ is the maximum load when considering the bidirectional load.

The specific algorithm of the burden rate index is shown in Table 1.

Table 1. Algorithm of injected and bidirectional burden rate.

\begin{tabular}{|c|c|c|}
\hline Index & $\begin{array}{c}\text { Calculation } \\
\text { method }\end{array}$ & Physical meaning \\
\hline $\begin{array}{c}\text { The injected } \\
\text { burden rate } \alpha_{1}\end{array}$ & $\begin{array}{c}\text { Neglect the negative } \\
\text { value of load data, } \\
\text { and the max positive } \\
\text { value is } P_{\text {ud-max }}\end{array}$ & $\begin{array}{c}\text { Burden rate index } \\
\text { that only considers } \\
\text { the economic } \\
\text { profit }\end{array}$ \\
\hline $\begin{array}{c}\text { The } \\
\text { bidirectional } \\
\text { burden rate } \alpha_{2}\end{array}$ & $\begin{array}{c}\text { Choose absolute } \\
\text { value of the load } \\
\text { data, and the max } \\
\text { value is } P_{\text {bd-max }}\end{array}$ & $\begin{array}{c}\text { Burden rate index } \\
\text { that consider } \\
\text { utilization } \\
\text { efficiency } \\
\text { objectively }\end{array}$ \\
\hline
\end{tabular}

\subsection{Specify the load rate}

From the equation $P_{e q}=\sum_{i=1}^{4} P_{L i}-P_{D G}$ drawn by Figure 1, it is pointed out that the fluctuation of $P_{\text {eq }}$ would be reduced if the characteristic of operating $D G$ is complementary with the load. However, the DG output is influenced greatly by season and weather. Moreover, the characteristic of DGs is usually inverse with the strategy of peak shaving. So the fluctuation of $P_{\text {eq }}$ would be larger with DG in operation. And the load rate would be smaller according to the definition, which means the index of transformer utilization efficiency would be smaller. Therefore, it is necessary to specify the load rate into injected load rate $\beta_{1}$ which represents the economic profit and the bidirectional load rate $\beta_{2}$ which represents the equipment utilization efficiency in substation.

The formula of the injected load rate is shown in (4).

$$
\beta_{1}=\frac{P_{u d-a v g}}{P_{u d-\max }}
$$

where $P_{\text {ud-avg }}$ is the average injected load. (5).

The formula of the bidirectional load rate is shown in

$$
\beta_{2}=\frac{P_{b d-a v g}}{P_{b d-\max }}
$$

where $P_{\text {bd-avg }}$ is the average bidirectional load.

The specific algorithm of the load rate index is shown in Table 2. 
Table 2. Algorithm of injected and bidirectional load rate.

\begin{tabular}{|c|c|c|}
\hline Index & Calculation method & Physical meaning \\
\hline $\begin{array}{c}\text { The injected } \\
\text { load rate } \beta_{1}\end{array}$ & $\begin{array}{c}\text { Neglecting the } \\
\text { negative value of load } \\
\text { data, the average } \\
\text { positive value is } P_{\text {ud- }} \\
\text { avg, and the max value } \\
\text { is } P_{\text {ud-max }}\end{array}$ & $\begin{array}{c}\text { Load rate index } \\
\text { that only considers } \\
\text { the economic } \\
\text { profit }\end{array}$ \\
\hline $\begin{array}{c}\text { The } \\
\text { bidirectional } \\
\text { load rate } \beta_{2}\end{array}$ & $\begin{array}{c}\text { Choose absolute value } \\
\text { of the load data, and } \\
\text { the average value is } \\
P_{\text {bd-avg while the max }} \\
\text { value is } P_{\text {bd-max }}\end{array}$ & $\begin{array}{c}\text { Load rate index } \\
\text { that consider } \\
\text { utilization } \\
\text { efficiency } \\
\text { objectively }\end{array}$ \\
\hline
\end{tabular}

\section{Application analysis}

Simulation cases are chosen from Shaoguan, a city located in south of China. Shaoguan is a typical city including distributed generation in China. In 2012, the average burden rate of Shaoguan is $36 \%$ while it is $35 \%$ in China, and the average load rate of Shaoguan is $79 \%$ while it is $80 \%$ nationwide. The management of power grid operation and electric equipment in Shaoguan is in average level of China. Therefore, the equipment utilization efficiency in Shaoguan is representative.

\subsection{Comparison of burden rate indexes}

According to the operation data of 37 transformers with $35 \mathrm{kV}$ class in Shaoguan in 2013, the calculating results of injected and bidirectional burden rate are given by means of Table 1. 3 .

The comparison result is shown in Figure 2 and Table

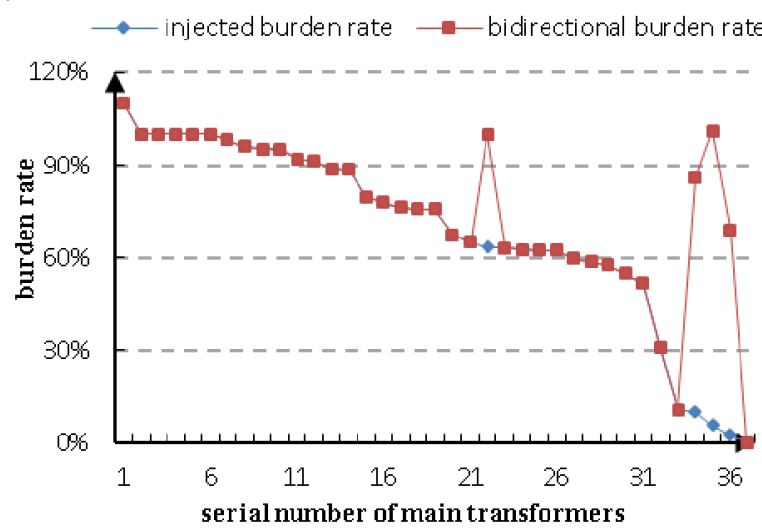

Figure 2. Comparison between injected burden rate $\alpha_{1}$ and bidirectional burden rate $\alpha_{2}$.

Table 3. Comparison between the proportion of two burden rates when in different interval.

\begin{tabular}{|c|c|c|c|}
\hline $\begin{array}{c}\text { Interval of } \\
\text { burden rate }\end{array}$ & $0 \sim 30 \%$ & $30 \% \sim 70 \%$ & $>70 \%$ \\
\hline $\begin{array}{c}\text { Proportion when } \\
\text { calculating by } \\
\text { injected burden } \\
\text { rate }\end{array}$ & $14 \%$ & $35 \%$ & $51 \%$ \\
\hline $\begin{array}{c}\text { Proportion when } \\
\text { calculating by } \\
\text { bidirectional } \\
\text { burden rate }\end{array}$ & $5 \%$ & $35 \%$ & $59 \%$ \\
\hline
\end{tabular}

From Figure 2 and Table 3, in interval of $0 \sim 30 \%$, the proportion calculating by bidirectional burden rate is reduced to $5 \%$, which is smaller than the proportion calculating by injected burden rate $14 \%$. In interval over $70 \%$, the proportion calculating by bidirectional burden rate is increased to $59 \%$, which is larger than the proportion calculating by injected burden rate $51 \%$. And in other intervals the outcome is the same between them. The results indicate that the injected burden rate which only considers the economic profit would cover up the objective utilization efficiency of transformer in some extent.

\subsection{Comparison of load rate indexes}

According to the operation data of 25 transformers with $35 \mathrm{kV}$ class in Shaoguan in 2013, the calculating result of injected and bidirectional load rate is given by means of Table 2.

The comparison result is shown in Figure 3 and Table 4.

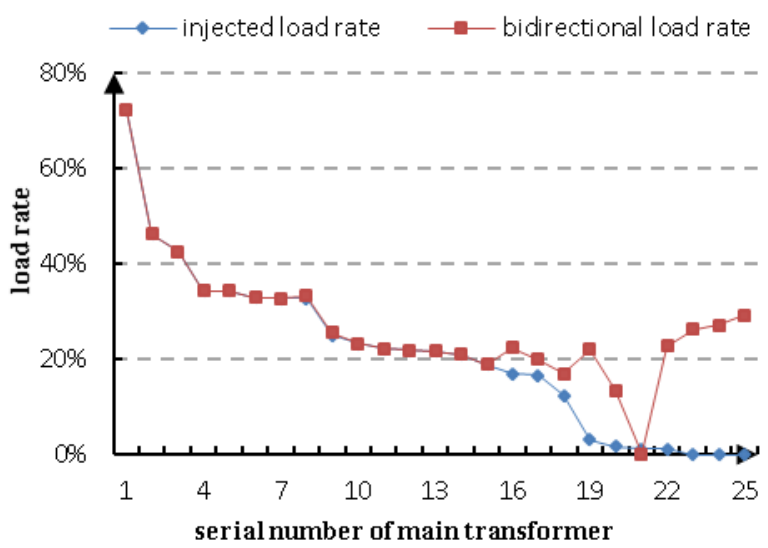

Figure 3. Comparison between injected load rate $\beta_{1}$ and bidirectional burden rate $\beta_{2}$.

Table 4. Comparison between the proportion of two load rates when in different interval.

\begin{tabular}{|c|c|c|c|}
\hline $\begin{array}{c}\text { Interval of load } \\
\text { rate }\end{array}$ & $0 \sim 15 \%$ & $15 \% \sim 30 \%$ & $>30 \%$ \\
\hline $\begin{array}{c}\text { Proportion when } \\
\text { calculating by } \\
\text { injected load rate }\end{array}$ & $32 \%$ & $36 \%$ & $32 \%$ \\
\hline $\begin{array}{c}\text { Proportion when } \\
\text { calculating by } \\
\text { bidirectional } \\
\text { load rate }\end{array}$ & $8 \%$ & $60 \%$ & $32 \%$ \\
\hline
\end{tabular}

From Figure 3 and Table 4, in interval of $0 \sim 15 \%$, the proportion calculating by bidirectional load rate is reduced to $8 \%$, which is smaller than the proportion calculating by injected load rate $32 \%$. In interval of $15 \% \sim 30 \%$, the proportion calculating by bidirectional load rate is increased to $60 \%$, which is larger than the proportion calculating by injected burden rate $36 \%$. And in other intervals, the outcome is the same between them. The results indicate that the injected load rate which only considers the economic profit would cover up the objective utilization efficiency of transformer in some extent. 


\section{Conclusion}

The equipment utilization efficiency is a significant index in economic evaluation of distribution network construction. However, the importance of it didn't take seriously before and the power supply enterprises only consider the contribution of transformer from the perspective of injected load, which is not objective to the substation including DGs.

This paper concentrates on the transformer utilization efficiency in substation. The burden rate and load rate are selected as the evaluation indexes, and specify them under the consideration of the particularity of distribution network including DGs. Then, compare the traditional injected burden rate $\alpha_{1}$ and the bidirectional burden rate $\alpha_{2}$, as well as the traditional injected load rate $\beta_{1}$ and the bidirectional load rate $\beta_{2}$. Compared with traditional evaluation index $\alpha_{1}$ and $\beta_{1}$, the application results show that the equipment utilization efficiency in substation is reflected more objectively by bidirectional calculation. Based on the proposed method, the bidirectional calculation and specific indexes should be considered in evaluation of equipment utilization efficiency in distributed network including DGs, which represent the contribution of equipment when the power transmission of DG is inverse.

\section{References}

1. Z. Q. Jiang, Z. Q. Guo, Z. Wei, Research on equipment utilization in computer composition and maintenance experiment curriculum, ICFCC, 3, 561564 (2010)

2. M. Ogawa, H. Endo, H. Fukuda, H. Kodama, T. Sugimoto, H. Soneda, M. Kondo, Cooling control restraining effects due to ICT equipment utilization of disturbance based on model predictive control for modular data center, CCA, 183-190 (2014)

3. E. Merrill, J. Bostwick, C. Gilhoi, K. Mikkelsen, Yield and equipment utilization improvements achieved through fab conversion to carbon fiber/PEEK wafer carriers and carbon fiber/polypropylene storage boxes, SEMI, 41-45 (2000)

4. S. Ge, L. Cao, H. Liu, Study on the best utilization rate of equipment in medium-voltage distribution network, ISGT Asia, 1-4 (2012)

5. W. Yang, H. Liu, Z. Wang, W. Cui, L. Cao, Study on evaluation index system of equipment utilization on distribution network, ISGT Asia, 1-5 (2012)

6. Z. Hu, Y. Zhang, C. Li, Utilization efficiency of electrical equipment within life cycle assessment: Indexes, analysis and a case, Energy, 88:885-896, (2015) 